\title{
The Absence of Rehabilitation During the ICU Stay of Elderly Patients is Associated with a Decreased Long-Term Autonomy.
}

\section{Fabrice Thiolliere}

Hospices Civils de Lyon

Bernard Allaouchiche

Hospices Civils de Lyon

Manon Marie

Hospices Civils de Lyon

AZUREA Study group

Hospices Civils de Lyon

Arnaud Friggeri

Hospices Civils de Lyon

Charles-Hervé VACHERON ( $\nabla$ charles-herve.vacheron@chu-lyon.fr)

Hospices Civils de Lyon https://orcid.org/0000-0003-1575-5847

Research

Keywords: elderly, autonomy, rehabilitation, intensive care unit.

Posted Date: August 13th, 2021

DOl: https://doi.org/10.21203/rs.3.rs-777046/v1

License: (9) (i) This work is licensed under a Creative Commons Attribution 4.0 International License.

Read Full License 


\section{Abstract}

\section{Background:}

The intensive care unit (ICU) stay is associated with a loss of autonomy, especially for elderly patients. We therefore conducted a study to estimate the impact of the rehabilitation performed during the ICU stay on the loss of autonomy at 6 months.

\section{Methods:}

We conducted an ancillary study of the multicenter FRAGIREA study, including patients between April 2018 and January 2019 aged over 70 years, admitted in ICU for an expected length of stay of more than 48 hours. We excluded the patients who died before day 180, who were lost to follow-up, and for whom the baseline autonomy ( $A D L)$ score was not available. We collected the baseline characteristics of patients, the ICU stay characteristics, and the 6-month follow-up. Were also collected the detailed rehabilitation therapy carried out during the ICU stay (passive mobilization, upright sitting, transfer to chair, standing, walking, and cycle ergometers.). Patients were classified into the rehabilitation (out of bed) or non-rehabilitation group, and the impact of rehabilitation on the decreased 6-month autonomy (loss of ADL score $>1$ point) was estimated after the selection of 17 potential confounders.

\section{Results:}

Among the 548 patients of the FRAGIREA cohort, 276 were included in the present study. Among them, 226 were rehabilitated and 50 were not. $220 / 276(80 \%)$ patients benefited from the transfer to chair as rehabilitation therapy, passive mobilization and transfer to upright sitting were also frequently performed. A decrease in the 6-month autonomy was observed for 63 (23\%) patients. After the elimination of potential confounders, non-rehabilitated patients had a greater risk of 6-month decreased autonomy (adjusted Odds Ratio 2.43, 95\% confidence interval [1.18; 4.98]).

\section{Conclusions:}

Rehabilitation during the ICU stay of elderly ICU patient survivors was associated with a lower decreased autonomy at 6 months.

Tweet. The absence of rehabilitation during the ICU stay of elderly patients is associated with 2.4 higher risk of a decreased 6 month autonomy

\section{Take Home Message}

- During their ICU stay, the elderly patients are at high risk of decreased autonomy.

- The impact of the rehabilitation on the long-term morbidity rest on low level of evidence.

- In our cohort of elderly ICU patient, the absence of rehabilitation was associated with a 2.4 higher risk of $6^{\text {th }}$ month decreased autonomy. 


\section{Introduction}

The mortality of patients admitted in intensive care units (ICU) has been decreasing over time, and more and more ICU survivors have to face the long term consequences of their stay (loss of autonomy, loss of quality of life...), especially elderly patients[1, 2].

During their stay, ICU patients receive a wide range of rehabilitation cares from ICU nurses or dedicated physical therapists. This rehabilitation is largely heterogeneous between centers[3].

The level of evidence related to the benefits for patients of performing rehabilitation during their ICU stay is currently low. Rehabilitation has been suggested to reduce ICU-acquired weakness (ICU-AW) and duration of mechanical ventilation, and to improve cognitive dysfunction and mobility at the end of the ICU stay[3-7]. However, so far no study has formally investigated the long-term impact of rehabilitation on the quality of life of ICU survivors.

In the present study, we hypothesized that performing rehabilitation during the ICU stay was associated with a lower risk of loss of autonomy among elderly ICU survivor at 6-month post-ICU admission.

\section{Material And Methods}

\section{Study design}

We conducted an ancillary study to the FRAGIREA study. The FRAGIREA cohort has been constituted from a multicenter prevalence study investigating the frequency of frailty and the management of elderly patients in ICU, as well as their status at day 180 post-ICU admission. The study was approved by the French data protection agency (Commission nationale de l'informatique et des libertés) and by an ethics committee (Comité de Protection des Personnes Ouest III). The protocol was submitted to clinicaltrial.gov (NCT03326635). The study was conducted in 40 French ICUs, with the support of the AZUREA network. Recruitment was conducted from April 2018 to January 2019. All patients included in the study were followed for 6 months or until death.

\section{Inclusion criteria}

All patients aged 70 years or older, who were hospitalized in an ICU of the participating center during the study period with an expected length of stay of more than 48 hours, were eligible for inclusion.

\section{Patient exclusion}

We excluded patients who died before day 180, who were lost to follow-up, or for whom the autonomy (ADL) score at inclusion was not available.

\section{Data collection}

The data collected consisted in: 
- Baseline characteristics: social and demographic (age, sex, height, weight, body mass index [BMI]), malnutrition (defined by a loss of weight $\geq 5 \%$ in the last month, $\geq 10 \%$ in the last 6 months, or a $\mathrm{BMI}<18.5$ ), pre-hospital residence (home with or without assistance, long term care), Charlson score, hospitalization in the previous 6 months, Fried and CFS (clinical frailty scale) scores, initial clinical autonomy (ADL score before admission)

- ICU stay characteristics: diagnosis category, severity at admission (SAPS II, simplified acute physiology score), mechanical ventilation, renal replacement therapy, need of vasopressor, and length of ICU stay. The type of physical therapy during ICU stay, and the number of days during which the therapy was performed was also documented. Briefly, a daily assessment was performed by a physician, who recorded whether the patient was mobilized, and which type of mobilization was performed.

- 6-month follow-up: place of living, and ADL score.

We documented 6 different physical therapy performed by a physical therapist or nurse. The passive mobilization (1), mainly for sedated patients, consists of the mobilization of the patient without any active movement from the patient. When the clinical status permits it, the patient could be transferred to upright sitting (2), with help to be sitting at the bed side. Also, the patient could be transfer to a chair (3), or standing (4) (putting the patient in the standing position). Finally, the patient could be helped to walk (5) in the ICU. We also documented the use of the cycle ergometers (6).

\section{Rehabilitation and decreased autonomy}

The rehabilitated patients were defined as the patients going out of bed during ICU stay, i.e. going to the chair (3), standing (4), or walking (5).

A decreased autonomy was defined by a loss of ADL score of more than 1 point between the preadmission state and the 6-month state.

\section{Objective}

We sought to assess the specific impact of rehabilitation during the ICU stay on elderly patient autonomy at 6 months, and to describe the rehabilitation practice among ICUs.

\section{Statistical analysis}

Continuous variables were expressed as median [interquartile range, IQR], and categorical variables were expressed as count (percentage). Differences between groups were tested with the Wilcoxon rank sum test, chi-square test, or Fisher test.

For the modeling of the impact of rehabilitation on the decreased autonomy, baseline and ICU stay characteristics were selected; this selection was based on clinician expertise and prior publication[8-11]. For baseline characteristics, we included: age, sex, BMI, place of living, Charlson score, previous hospitalization in the previous 6 months, Fried and CFS scores, loss of weight, loss of appetite, malnutrition. For ICU stay characteristics, we included: diagnosis category, SAPS II, mechanical 
ventilation status, renal replacement therapy, vasopressor use during the ICU stay, and length of ICU stay. Three variables had a total of seven missing data, which were imputed through Multivariate Imputation by Chained Equations.

All confounders were included in an augmented backward elimination, with a threshold for relative change-in-estimate criterion at $10 \%$, and the criterion for assessing the adequacy of the model was the Akaike information criterion. The rehabilitation was classified as a passive variable, and every other variable as active variable.

To assess whether the center effect had to be taken into account, we compared the final model used to the same model while adding a mixed term on the center on the intercept (mixed model 1) and both on the intercept and the rehabilitation status (mixed model 2). These two models were compared using the likelihood ratio test to the final model. For the variable selected in the final model, we estimated the adjusted odds ratio $(\mathrm{OR})$ and their associated $95 \%$ confidence interval $(95 \% \mathrm{Cl})$. The area under the receiver operating characteristic curve (AUROC) of the model was estimated, and expressed with its associated $95 \% \mathrm{Cl}$.

P-values $<0.05$ were considered as significant. Analyses were performed using R software version 4.1.0 and the package abe and mice.

\section{Results}

Among the 548 patients included in the FRAGIREA cohort, 272 were excluded from the present study (211 died before day 180, 60 were lost to follow-up, and 1 had no available baseline autonomy assessment; Supplementary Fig. 1). Finally, 276 patients were included in the study, 226 benefited from rehabilitation during their ICU stay and 50 did not.

Both groups were comparable regarding most of the characteristics collected, such as age, sex, place of leaving, severity at admission, or diagnostic category. However, the median [IQR] CFS score was higher in the no-rehabilitation group (4 [3-4]) compared to the rehabilitation group (3 [2-4]), and the median [IQR] ICU stay was longer (no-rehabilitation group: 8 [5-13] days; rehabilitation group: 6 [4-7] days). The median [IQR] baseline ADL score was 6.0 [5.5-6.0] in both groups (Table 1).

\section{Description of the rehabilitation performed in the ICU}

A total of $220 / 276(80 \%)$ patients benefited from the transfer to chair as rehabilitation therapy. Considering the number of days this therapy was performed, patients spent a median [IQR] 46 [31-62] \% of their ICU stay with a passage to the chair. The two other main physical therapies performed were passive mobilization (for 152 (55\%) patients) and transferring to upright sitting (for 114 (41\%) patients; Table 2). 
There were 89 (32\%) patients for whom standing rehabilitation was performed, and 52 (19\%) who walked in the ICU. The use of the cycle ergometers was marginal (13 patients, 5\%; Table 2).

\section{Progression of the autonomy}

At the 6th month, the place of living was similar in both rehabilitated and non-rehabilitated patient groups. However, non-rehabilitated patients had a lower median [IQR] ADL score (4.5 [3.0-6.0] vs 6.0 [4.5$6.0]$ ) at 6-month and were more in proportion to have a decreased autonomy ( $36 \%$ vs $20 \%$; Table 1 ). A detailed description of the ADL score by dimension is available in supplementary table 1.

The progression of the autonomy was also illustrated using a categorical alluvial plot, in which the absence of deficit was considered as an ADL score of 6 , a minor deficit as a score of 5 or 5.5 , a moderate deficit as a score of 4 or 4.5 , and a severe deficit as a score of less than 4 (Fig. 1). The decrease in autonomy was homogenous for both rehabilitated and non-rehabilitated patients considering all the dimensions of the ADL score (Fig. 2).

\section{Modelling of the decreased autonomy at 6 months}

The final model selected rehabilitation, diagnosis category, and baseline CFS as predictors of the 6-month decreased autonomy. Rehabilitation was associated with a significant decreased risk of autonomy loss (OR [95\% Cl]: 0.41 [0.20; 0.84]; $\mathrm{p}=0.0154$ ); Table 3). In other words, non-rehabilitated patients had a greater risk of 6-month decreased autonomy (OR [95\% Cl]: 2.43 [1.18; 4.98]). The final model had an AUROC [95\% Cl] of 0.734 [0.666; 0.802]; Hosmer and Lemeshow goodness of fit $p$-value $=0.772$.

Center effect

Taking into account the center effect did not improve the final model selected, neither considering the mixed model 1 (deviance: 268.7 vs $267.1 ; p=0.205$ ) nor the mixed model 2 (deviance: 268.7 vs $265.5 ; p=$ $0.531)$. Therefore, the non-mixed logistic regression model was used for the final analysis.

\section{Discussion}

In our study, we showed that the absence of rehabilitation for elderly ICU patients was associated with a 2.4 higher risk of decreased autonomy at 6 months after admission. We also provided a descriptive overview of the physical therapy performed in the ICU participating in the study.

Rehabilitation in intensive care unit

In their one-day prevalence study in 2011 , Nydahl et al. have found that $77 \%$ of ICU patients were not mobilized out of bed, and that a very low proportion of patients were standing or walking outside of their 
bed (4\%)[12]. Another study, performed in 2014 on adult patient with acute respiratory failure, has revealed that only a third of patients benefited from physical therapy[13]. Patients benefiting from physical therapy were more likely progress out of bed[13].

In their randomized controlled trial, Scweicker et al. have showed that a strategy of whole-body rehabilitation (physical and occupational therapy in the earliest days of critical illness; interruption of sedation) was associated with a better functional outcome at hospital discharge, a shorter duration of delirium, and more numerous ventilator-free days[7]. In their before/after study, Needham et al. have showed that, with the use of a quality improvement program focusing on reducing deep sedation and increasing the number of rehabilitation sessions (by increasing the number of therapists), the delirium, and physical and functional mobility were improved and associated with a shorter length of stay[2]. Needless to say, rehabilitation also increases the quality of life and patient's mood during the ICU stay, because the ability to go out of bed represents a recovery of autonomy and a landmark for patients, as they do not need to rely entirely on nurses for every activity[6]. Some study have also reported the interest of "intensive rehabilitation" compared to "standard rehabilitation": for example, the EPICC multicenter randomized controlled trial has reported no benefit of the intensive rehabilitation compared with standard care regarding the 6-month physical function[14]. Likewise, Maffei et al. have not reported any significant benefit of intensive rehabilitation for ICU patients admitted for liver transplant. However, there is still no conclusive evidence regarding the benefit for patients of rehabilitation therapy in itself during intensive care stay. A 2018 Cochrane review has concluded that there is insufficient evidence to concluded on the effect of early mobilization on critical care patients and had encouraged further studies to investigate this topic.

Regarding the definition of the rehabilitation, several options are offered to clinicians. For example, there is the possibility to use the ICU Mobility Scale[15]: ranging from 0 to 10, this 11-level scale allows clinicians to evaluate daily the intensity of the rehabilitation[16]. Paton et al. have used the highest Intensive Care Mobility Scale Level achieved during the length of stay as a predictor of quality of life. In our study, we choose a simpler criterion ("Out of bed during the ICU stay") because it represents the goal of rehabilitation (i.e. standing and walking before hospital discharge). This is an objective that has been used repeatedly in published studies. However, neither the use of the ICU mobility scale nor our criterion provide an accurate representation of rehabilitation. Indeed, they do not take into account the duration of the ICU stay, the possibility (or not) to be rehabilitated, or the duration of the rehabilitation performed. Future studies should focus on the rehabilitation as a multivariable endpoint, including the intensity of rehabilitation, the number of rehabilitation sessions, the length of ICU stay, and the possibility (or not) to be rehabilitated.

Prediction of the 6-month disability

Studies focusing on the predictor of the 6-month disability are rare. In our final model, we included rehabilitation, diagnosis category, and baseline CFS. Recently, Higgins et al. have modeled the presence of new disability or death post-ICU stay[8]. In their final model, not surprisingly, the APACHE III score and 
the age were predictors of their composite outcome, as they are well-known predictors of mortality. By focusing solely on the presence of decreased autonomy among elderly survivors, age was not associated with the risk of presenting a new disability in our study. However, frailty was included in the final model, confirming the importance of a specific evaluation of elderly patients during their ICU stay. Indeed, in the study of Nakajima et al., CFS was associated with mobility impairment at ICU discharge in septic patients receiving early rehabilitation[17].

In their recent systematic review, Haines et al. have identified only two studies focusing of the development of model to predict the physical function post-ICU discharge. Detsky et al. have found that the APACHE III score, being a medical patient, older age, nonwhite race, recent hospitalization, prior transplantation, and history of cancer or of neurologic or liver disease were predictors of patients not returning to their baseline status at 6 months[9]. In another study from Schandl et al. focusing on the 2month new onset disability, 4 predictors have been identified: low educational level, impaired core stability, fractures, and ICU length of stay longer than 2 days. Interestingly, the authors did not include in the variable selection process the frailty of patients, but their final model included the impaired core stability and the presence of fractures, which are probably highly collinear with frailty.

Studying the impact of rehabilitation

While several cohort studies have tried to demonstrate the benefit of rehabilitation during the ICU stay, the researcher community face several issues regarding the collinearity between the rehabilitation and the mortality.

Indeed, the most stable patients will benefit from early physical therapy and will most likely have a low mortality rate. On the other hand, unstable patients (too severe or too unstable) have a high mortality rate and cannot benefit from rehabilitation, thus leading to a bias regarding rehabilitation. There is also a competing risk between the intensity of rehabilitation (number of sessions) and the length of ICU stay, as patients in ICU for a short length of stay and displaying favorable outcome will benefit from a limited number of physical therapy sessions, and patients in ICU for longer durations and presenting multiple complications will benefit from a higher number of physical therapy sessions but still display an unfavorable outcome.

\section{Conclusion}

Our study suggests that performing rehabilitation during the ICU stay allows a lower autonomy loss at 6 months post-admission. To assess the unbiased impact of the rehabilitation among ICU patients on mortality, or other endpoints (quality of life, autonomy), future studies need some strong design (randomized controlled trial) and an adequate characterization of the rehabilitation.

\section{Declarations}


Conflicts of Interest and Source of Funding: The authors have disclosed that they do not have any conflicts of interest;

Ethical Approval and Consent to participate: The study was approved by the appropriate institutional research ethics committee (Hospices Civils de Lyon) and we certify that the study was performed in accordance with the ethical standards as laid down in the 1964 Declaration of Helsinki and its later amendments or comparable ethical standards.

Informed consent: Informed consent was obtained from all individual participants included in the study Consent for publication: Every author approved the article for publication

Availability of supporting data: Confidential

Conflicts of Interest and Source of Funding. The authors disclose no conflict of interest.

Conflicts of interest: None

Authors' individual contributions to the study:

$\mathrm{CHV}$ : This author wrote the first draft of the manuscript, reviewed the manuscript, and performed the statistical analysis; FT, BA, AF: These authors participated in data collection, conception, interpretation of the data, and revising the manuscript substantially. Other authors participated in the interpretation of the data, data collection, and revising the manuscript substantially. All authors read and approved the final manuscript.

Acknowledgements: The authors would like to thank Hélène Boyer (Hospices Civils de Lyon) for help in manuscript preparation.

AZUREA Study group: 


\begin{tabular}{|c|c|c|c|c|}
\hline Name & First Name & City & Hospital & MAIL \\
\hline ARGAUD & LAURENT & Lyon & $\begin{array}{l}\text { HCL, HEH, N } \\
\text { REA }\end{array}$ & laurent.argaud@chu-lyon.fr \\
\hline FLOCCARD & BERNARD & Lyon & $\begin{array}{l}\text { HCL, HEH, G } \\
\text { REA }\end{array}$ & thomas.rimmele@chu-lyon,fr \\
\hline RIMMELE & THOMAS & Lyon & $\begin{array}{l}\text { HCL, HEH, P } \\
\text { REA }\end{array}$ & thomas.rimmele@chu-lyon,fr \\
\hline LEVRAT & ALBRICE & Annecy & CH ANNECY & alevrat@ch-annecygenevois.fr \\
\hline LEDECHOWSKI & STANISLAS & Bourgoin & CH BOURGOIN & s.ledochowski@gmail.com \\
\hline BRUYERE & REMI & $\begin{array}{l}\text { Bourg en } \\
\text { Bresse }\end{array}$ & $\begin{array}{l}\text { CH BOURG EN } \\
\text { BRESSE }\end{array}$ & rbruyere@ch-bourg01.fr \\
\hline SCHWEBEL & CAROLE & Grenoble & $\begin{array}{l}\text { CHU GRENOBLE } \\
\text { Réa Med }\end{array}$ & cschwebel@chu-grenoble.fr \\
\hline ZERR & Benedicte & Chambéry & CH CHAMBERY & $\begin{array}{l}\text { jean.marc.thouret@ch- } \\
\text { metropole-savoie.fr }\end{array}$ \\
\hline JARRIGE & LUC & Moulins & CH MOULINS & I.jarrige@ch-moulins-yzeure.fr \\
\hline BLANC & QUENTIN & Valence & CH VALENCE & qblanc@ch-valence.fr \\
\hline MOREL & JEROME & $\begin{array}{l}\text { Saint } \\
\text { Etienne }\end{array}$ & $\begin{array}{l}\text { CHU SAINT } \\
\text { ETIENNE Réa } \\
\text { Poly }\end{array}$ & jerome.morel@chu-st-etienne.fr \\
\hline BALDESI & OLIVIER & $\begin{array}{l}\text { Aix en } \\
\text { Provence }\end{array}$ & $\begin{array}{l}\text { CH AIX EN } \\
\text { PROVENCE }\end{array}$ & obaldesi@ch-aix.fr \\
\hline PLANTEFEVE & GAËTAN & Argenteuil & $\begin{array}{l}\mathrm{CH} \\
\text { ARGENTEUIL }\end{array}$ & $\begin{array}{l}\text { gaetan.plantefeve@ch- } \\
\text { argenteuil.fr }\end{array}$ \\
\hline SEGUIN & PHILIPPE & Rennes & $\begin{array}{l}\text { CHU RENNES } \\
\text { Réa Chir }\end{array}$ & philippe.seguin@chu-rennes.fr \\
\hline $\begin{array}{l}\text { DAHYOT- } \\
\text { FIZELIER }\end{array}$ & CLAIRE & Poitiers & $\begin{array}{l}\text { CHU POITIERS } \\
\text { Réa Chir }\end{array}$ & $\begin{array}{l}\text { claire.dahyot-fizelier@chu- } \\
\text { poitiers.fr }\end{array}$ \\
\hline BONNIVARD & MICHEL & Montauban & $\begin{array}{l}\mathrm{CH} \\
\text { MONTAUBAN }\end{array}$ & m.bonnivard@ch-montauban.fr \\
\hline ROUSTAN & $\mathrm{J}$ & Montauban & $\begin{array}{l}\mathrm{CH} \\
\text { MONTAUBAN }\end{array}$ & j.roustan@ch-montauban.fr \\
\hline VIMEUX & $S$ & Montauban & $\begin{array}{l}\mathrm{CH} \\
\text { MONTAUBAN }\end{array}$ & s.vimeux@ch-montauban.fr \\
\hline MOFREDJ & ALI & $\begin{array}{l}\text { Salons de } \\
\text { Provence }\end{array}$ & $\begin{array}{l}\text { CH SALONS DE } \\
\text { PROVENCE }\end{array}$ & ali.mofredj@ch-salon.fr \\
\hline ALAYA & Sami & $\begin{array}{l}\text { Salons de } \\
\text { Provence }\end{array}$ & $\begin{array}{l}\text { CH SALONS DE } \\
\text { PROVENCE }\end{array}$ & sami.alaya@ch-salon.fr \\
\hline
\end{tabular}




\begin{tabular}{|c|c|c|c|c|}
\hline MAAMAR & Adel & Rennes & $\begin{array}{l}\text { CHU RENNES } \\
\text { Réa Med }\end{array}$ & adel.maamar@chu-rennes.fr \\
\hline BADIE & JULIO & Belfort & CH BELFORT & Julio.BADIE@hnfc.fr \\
\hline SOUWEINE & BERTRAND & $\begin{array}{l}\text { Clermont } \\
\text { Ferrand }\end{array}$ & $\begin{array}{l}\text { CHU } \\
\text { CLERMONT } \\
\text { FERRAND Réa } \\
\text { Med }\end{array}$ & $\begin{array}{l}\text { bsouweine@chu- } \\
\text { clermontferrand.fr }\end{array}$ \\
\hline CHOUKROUN & GERALD & Evry & $\begin{array}{l}\text { CH SUD } \\
\text { FRANCILIEN }\end{array}$ & guillaume.chevrel@chsf.fr \\
\hline FONTAINE & ORIANE & Mayotte & CH MAYOTTE & o.fontaine@chmayotte.fr \\
\hline CONSTANTIN & $\begin{array}{l}\text { JEAN } \\
\text { MICHEL }\end{array}$ & $\begin{array}{l}\text { Clermont } \\
\text { Ferrand }\end{array}$ & $\begin{array}{l}\text { CHU } \\
\text { CLERMONT } \\
\text { FERRAND Réa } \\
\text { Chir }\end{array}$ & efutier@chu-clermontferrand.fr \\
\hline GAINIER & MARC & Marseille & $\begin{array}{l}\text { AP-HM LA } \\
\text { TIMONE Réa } \\
\text { Med }\end{array}$ & marc.gainnier@ap-hm.fr \\
\hline MISSET & BENOIT & Rouen & $\begin{array}{l}\text { CHU ROUEN Réa } \\
\text { Med }\end{array}$ & Fabienne.Tamion@chu-rouen.fr \\
\hline ORBAN & $\begin{array}{l}\text { JEAN } \\
\text { CLAUDE }\end{array}$ & Nice & $\begin{array}{l}\text { CHU NICE } \\
\text { Pasteur } 2 \text { RMC }\end{array}$ & orban.jc@chu-nice.fr \\
\hline REIGNIER & JEAN & Nantes & $\begin{array}{l}\text { CHU NANTES } \\
\text { Réa Med }\end{array}$ & Jean.Reignier@univ-nantes.fr \\
\hline DOISE & $\begin{array}{l}\text { JEAN- } \\
\text { MARC }\end{array}$ & $\begin{array}{l}\text { Chalon sur } \\
\text { Saône }\end{array}$ & $\begin{array}{l}\text { CH CHALONS } \\
\text { SUR SAONE }\end{array}$ & jean-marc.doise@ch-chalon71.fr \\
\hline MILLET & OLIVIER & Montélimar & $\begin{array}{l}\text { CH } \\
\text { MONTELIMAR }\end{array}$ & olivier.millet@ch-montelimar.fr \\
\hline FAVIER & LAURENT & Bézier & CH BEZIERS & laurent.favier@ch-beziers.fr \\
\hline JANY & Berangere & Bézier & CH BEZIERS & berangere.jany@ch-beziers.fr \\
\hline RAVAN & RAMIN & Vichy & $\mathrm{CH}$ VICHY & ramin.ravan@ch-vichy.fr \\
\hline ROUX & Delphine & Vichy & $\mathrm{CH}$ VICHY & delphine.roux@ch-vichy.fr \\
\hline BERTRAND & $\begin{array}{l}\text { Pierre } \\
\text { Marie }\end{array}$ & Cannes & $\begin{array}{l}\text { CH CANNES Rea } \\
\text { Poly }\end{array}$ & N.CLEMENT@ch-cannes.fr \\
\hline BELE & Nicolas & Fréjus & CH FREJUS & nicolasbele@free.fr \\
\hline MALAQUIN & Stéphanie & Amiens & Réa Chir & $\begin{array}{l}\text { malaquin.stephanie@chu- } \\
\text { amiens.fr }\end{array}$ \\
\hline GUINOT & $\begin{array}{l}\text { Pierre } \\
\text { Grégoire }\end{array}$ & Dijon & Réa Chir & guinotpierregregoire@gmail.com \\
\hline QUENOT & Jean Pierre & Dijon & CHU DIJON Rea & jean-pierre.quenot@chu-dijon.fr \\
\hline
\end{tabular}




$\begin{array}{llll}\text { BOUNES } & \text { Fanny } & \begin{array}{l}\text { Toulouse } \\ \text { RANGUEIL }\end{array} & \begin{array}{l}\text { CHU TOULOUSE } \\ \text { Rea Poly }\end{array}\end{array}$

\begin{tabular}{lllll} 
KOUBI & Claude & Nice & HPGS NICE & ckoubi@hpgs,fr \\
DANIN & P & Nice & HPGS NICE & pdanin@hpgs,fr \\
\hline
\end{tabular}

\section{References}

1. Kaukonen K-M, Bailey M, Suzuki S, Pilcher D, Bellomo R. Mortality related to severe sepsis and septic shock among critically ill patients in Australia and New Zealand, 2000-2012. JAMA. 2014;311:1308-16.

2. Needham DM, Davidson J, Cohen $\mathrm{H}$, Hopkins RO, Weinert $\mathrm{C}$, Wunsch $\mathrm{H}$, et al. Improving long-term outcomes after discharge from intensive care unit: report from a stakeholders' conference. Crit Care Med. 2012;40:502-9.

3. TEAM Study Investigators. Hodgson C, Bellomo R, Berney S, Bailey M, Buhr H, et al. Early mobilization and recovery in mechanically ventilated patients in the ICU: a bi-national, multi-centre, prospective cohort study. Crit Care Lond Engl. 2015;19:81.

4. Wilcox ME, Brummel NE, Archer K, Ely EW, Jackson JC, Hopkins RO. Cognitive dysfunction in ICU patients: risk factors, predictors, and rehabilitation interventions. Crit Care Med. 2013;41:81-98.

5. Jolley SE, Bunnell AE, Hough CL. ICU-Acquired Weakness Chest. 2016;150:1129-40.

6. Needham DM. Mobilizing patients in the intensive care unit: improving neuromuscular weakness and physical function. JAMA. 2008;300:1685-90.

7. Schweickert WD, Pohlman MC, Pohlman AS, Nigos C, Pawlik AJ, Esbrook CL, et al. Early physical and occupational therapy in mechanically ventilated, critically ill patients: a randomised controlled trial. Lancet Lond Engl. 2009;373:1874-82.

8. Higgins AM, Neto AS, Bailey M, Barrett J, Bellomo R, Cooper DJ, et al. Predictors of death and new disability after critical illness: a multicentre prospective cohort study. Intensive Care Med [Internet]. 2021 [cited 2021 Jun 13]; Available from: https://doi.org/10.1007/s00134-021-06438-7.

9. Detsky ME, Harhay MO, Bayard DF, Delman AM, Buehler AE, Kent SA, et al. Six-Month Morbidity and Mortality among Intensive Care Unit Patients Receiving Life-Sustaining Therapy. A Prospective Cohort Study. Ann Am Thorac Soc. 2017;14:1562-70.

10. Haines KJ, Hibbert E, McPeake J, Anderson BJ, Bienvenu OJ, Andrews A, et al. Prediction Models for Physical, Cognitive, and Mental Health Impairments After Critical Illness: A Systematic Review and Critical Appraisal. Crit Care Med. 2020;48:1871-80. 
11. Schandl A, Bottai M, Holdar U, Hellgren E, Sackey P. Early prediction of new-onset physical disability after intensive care unit stay: a preliminary instrument. Crit Care Lond Engl. 2014;18:455.

12. Nydahl P, Ruhl AP, Bartoszek G, Dubb R, Filipovic S, Flohr H-J, et al. Early mobilization of mechanically ventilated patients: a 1-day point-prevalence study in Germany. Crit Care Med. 2014;42:1178-86.

13. Jolley SE, Moss M, Needham DM, Caldwell E, Morris PE, Miller RR, et al. Point Prevalence Study of Mobilization Practices for Acute Respiratory Failure Patients in the United States. Crit Care Med. 2017;45:205-15.

14. Wright SE, Thomas K, Watson G, Baker C, Bryant A, Chadwick TJ, et al. Intensive versus standard physical rehabilitation therapy in the critically ill (EPICC): a multicentre, parallel-group, randomised controlled trial. Thorax. 2018;73:213-21.

15. Tipping CJ, Bailey MJ, Bellomo R, Berney S, Buhr H, Denehy L, et al. The ICU Mobility Scale Has Construct and Predictive Validity and Is Responsive. A Multicenter Observational Study. Ann Am Thorac Soc. 2016;13:887-93.

16. Paton M, Lane R, Paul E, Cuthburtson GA, Hodgson CL. Mobilization During Critical Illness: A Higher Level of Mobilization Improves Health Status at 6 Months, a Secondary Analysis of a Prospective Cohort Study. Crit Care Med. 2021.

17. Nakajima H, Nishikimi M, Shimizu M, Hayashi K, Inoue T, Nishida K, et al. Clinical Frailty Scale Score Before ICU Admission Is Associated With Mobility Disability in Septic Patients Receiving Early Rehabilitation. Crit Care Explor. 2019;1:e0066.

\section{Tables}

\section{Table 1: Main baseline characteristics}




\begin{tabular}{|c|c|c|c|}
\hline & $\begin{array}{l}\text { Not rehabilitated patients } \\
(n=50)\end{array}$ & $\begin{array}{l}\text { Rehabilitated } \\
\text { patients } \\
(n=226)\end{array}$ & $\begin{array}{l}\mathrm{p} \\
\text { value }\end{array}$ \\
\hline \multicolumn{4}{|l|}{ Baseline characteristics } \\
\hline Age, years & 79 [74-83] & 77 [73-82] & 0.187 \\
\hline Male sex & $28(56)$ & $130(57)$ & 0.969 \\
\hline Height, cm & $168[160-174]$ & $167[160-174]$ & 0.847 \\
\hline Weight, kg & 70 [63-85] & $74[64-88]$ & 0.363 \\
\hline $\mathrm{BMI}, \mathrm{kg} / \mathrm{m}^{2}$ & 25 [23-28] & $26[23-30]$ & 0.213 \\
\hline Malnutrition & $15(30)$ & $48(21)$ & 0.271 \\
\hline Place of living & & & 0.260 \\
\hline Home & $41(82)$ & $188(83)$ & \\
\hline Home with assistance & $9(18)$ & $29(13)$ & \\
\hline Long term care & $0(0)$ & $9(4)$ & \\
\hline Charlson score & $2[0-3]$ & $2[0-3]$ & 0.679 \\
\hline $\begin{array}{l}\text { Hospitalization within the previous } 6 \\
\text { month }\end{array}$ & $15(30)$ & $75(33)$ & 0.789 \\
\hline Fried score & $3[1-4]$ & $2[1-3]$ & 0.084 \\
\hline Frailty & $28(56)$ & $95(42)$ & 0.101 \\
\hline CFS & $4[3-4]$ & $3[2-4]$ & 0.019 \\
\hline Frailty & $11(22)$ & $32(14)$ & 0.243 \\
\hline ADL score & $6.0[5.5-6.0]$ & $6[5.5-6.0]$ & 0.242 \\
\hline \multicolumn{4}{|l|}{ ICU stay } \\
\hline Diagnosis category & & & 0.095 \\
\hline Medical & $32(64)$ & $153(68)$ & \\
\hline Planned surgery & $1(2)$ & $21(9)$ & \\
\hline Emergent surgery & $17(34)$ & $52(23)$ & \\
\hline SAPS II & 47 [38-58] & $48[38-60]$ & 0.836 \\
\hline Mechanical ventilation & $24(48)$ & $99(44)$ & 0.370 \\
\hline Renal replacement therapy & $3(6)$ & $17(7)$ & 1.000 \\
\hline
\end{tabular}




\begin{tabular}{|llll|}
\hline Vasopressor & $34(68)$ & $126(56)$ & 0.153 \\
\hline At 6 month & $8[5-13]$ & $6[4-7]$ & $<0.001$ \\
\hline Place of living & & & 0.441 \\
\hline Home & $26(54)$ & $133(59)$ & \\
Home with help & $12(25)$ & $61(27)$ & \\
\hline Institution & $7(15)$ & $25(11)$ & 0.001 \\
\hline Hospitalized & $3(6)$ & $6(3)$ & \\
\hline ADL score & $4.5[3.0-6.0]$ & $6.0[4.5-6.0]$ & $45(20)$ \\
\hline Decreased autonomy & $18(36)$ & 45 , days & \\
\hline
\end{tabular}

Data are expressed as count (percentage) or median [interquartile range, IQR]. p values for the comparison between groups.

Abbreviations: $B M I$, body mass index; $A D L$, activities of daily living; SAPS, simplified acute physiology score; ICU, intensive care unit; CFS, clinical frailty scale

\section{Table 2: Description of the rehabilitation performed during the intensive care stay.}




\begin{tabular}{|c|c|c|c|}
\hline & $\begin{array}{l}\text { No decreased autonomy } \\
(n=213)\end{array}$ & $\begin{array}{l}\text { Decreased autonomy } \\
(n=63)\end{array}$ & $\begin{array}{l}\text { Total } \\
(n=276)\end{array}$ \\
\hline Passive mobilization, $n$ (\%) & $111(52)$ & $41(65)$ & $152(55)$ \\
\hline Duration, days & $4[2-7]$ & $5[3-6]$ & $4[2-7]$ \\
\hline$\%$ of the ICU stay, $\%$ & $51[28-71]$ & $63[40-75]$ & 53 [29-74] \\
\hline Transfer to upright sitting, $n(\%)$ & $93(44)$ & $21(33)$ & $114(41)$ \\
\hline Duration, days & $2[1-4]$ & $3[1-4]$ & $2[1-4]$ \\
\hline$\%$ of the ICU stay, $\%$ & $33[14-50]$ & $14[8-50]$ & $33[12-50]$ \\
\hline Transfer to chair, $n(\%)$ & $178(84)$ & $42(67)$ & $220(80)$ \\
\hline Duration, days & $3[2-6]$ & $4[2-8]$ & $4[2-6]$ \\
\hline$\%$ of the ICU stay, $\%$ & 49 [32-67] & $40[26-60]$ & 46 [31-62] \\
\hline Standing, $n(\%)$ & $75(35)$ & $14(22)$ & $89(32)$ \\
\hline Duration, days & $2[2-3]$ & $4[1-5]$ & $2[1-4]$ \\
\hline$\%$ of the ICU stay, \% & 33 [18-50] & 29 [15-49] & 33 [17-50] \\
\hline Walking, $n(\%)$ & $49(23)$ & $3(5)$ & $52(19)$ \\
\hline Duration, days & $2[1-4]$ & $2[1-3]$ & $2[1-4]$ \\
\hline$\%$ of the ICU stay, $\%$ & $23[12-32]$ & $27[17-40]$ & $24[12-34]$ \\
\hline Cycle Ergometers, $n$ (\%) & $8(4)$ & $5(8)$ & $13(5)$ \\
\hline Duration, days & $1[1-2]$ & $4[1-6]$ & $1[1-4]$ \\
\hline$\%$ of the ICU stay, $\%$ & 9 [7-21] & 18 [11-20] & 11 [7-20] \\
\hline
\end{tabular}

Data are expressed as count (percentage) or median [interquartile range, IQR].

Abbreviation: ICU, intensive care unit.

Table 3: Modeling of the decreased autonomy at 6 months post admission in intensive care unit. 


\begin{tabular}{|lll|}
\hline & Odds Ratio [95\%Cl] & p value \\
\hline Rehabilitation & $0.41[0.20 ; 0.84]$ & 0.0154 \\
\hline Diagnosis category & & \\
\hline Medical & $1-$ & \\
\hline Planned surgery & $0.16[0.02 ; 1.3]$ & 0.3815 \\
\hline Emergent surgery & $1.35[0.69 ; 2.67]$ & 0.3815 \\
\hline Baseline CFS & $1.23[0.99 ; 1.52]$ & 0.0574 \\
\hline
\end{tabular}

Results are expressed as Odds ratio $[95 \% \mathrm{Cl}]$.

AUC: 0.734 [0.666; 0.802]

Abbreviation: CFS, clinical frailty score; $\mathrm{Cl}$, confidence interval.

\section{Figures}

No Rehabilitation

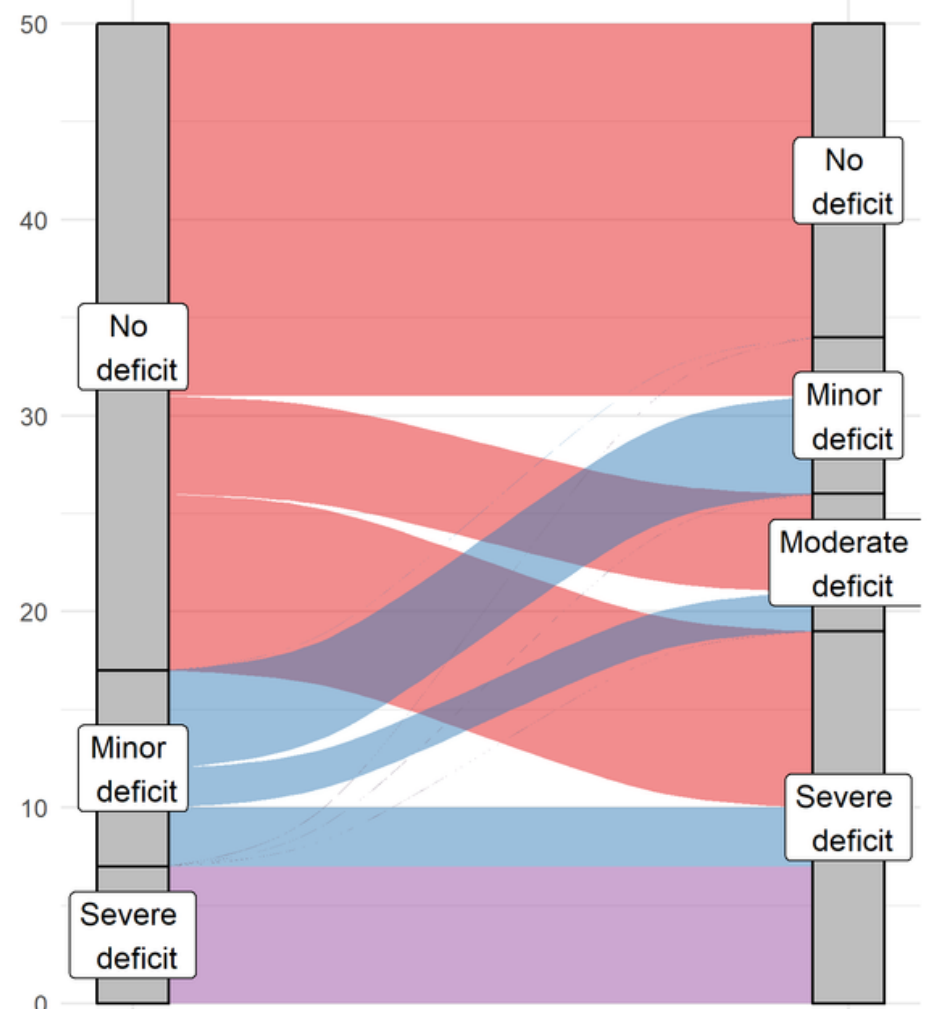

Day 0

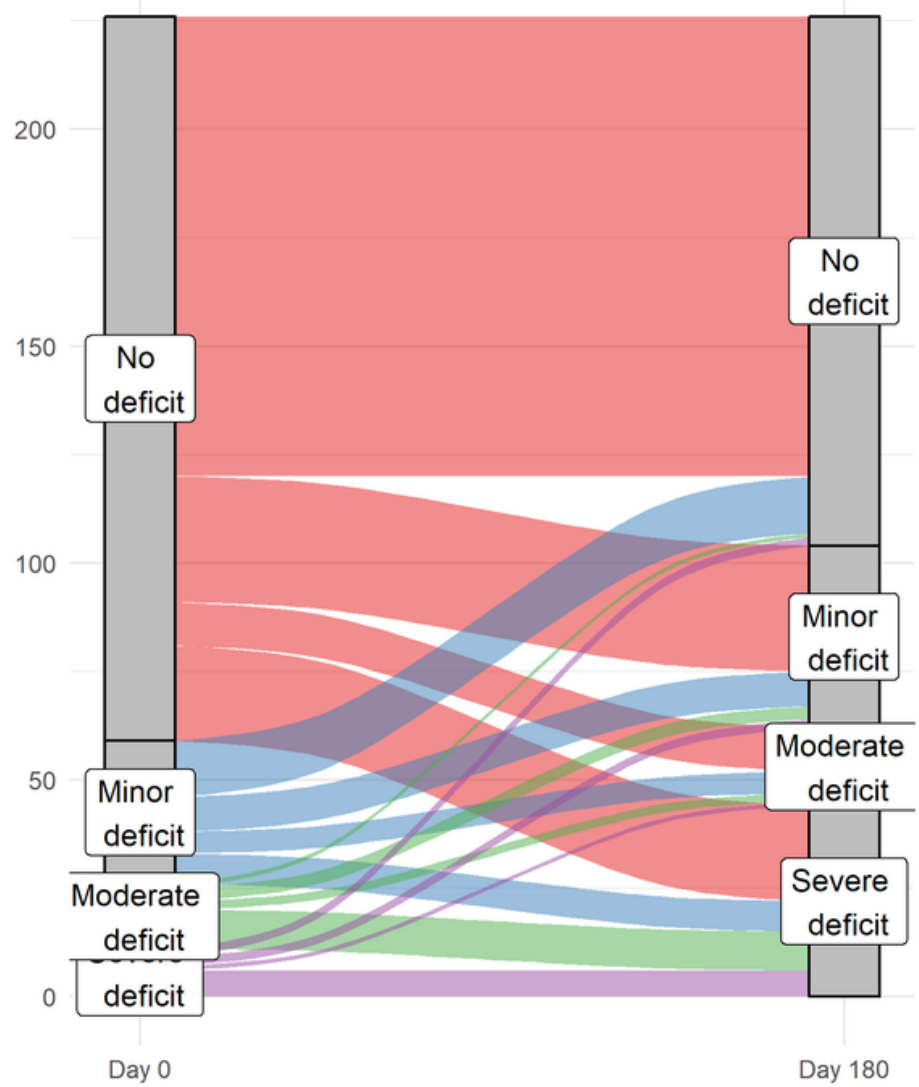

Figure 1 
Alluvial plot No deficit: $A D L$ score = 6; Minor deficit: $5 \leq A D L$ score $<6$; Moderate deficit: $4 \leq A D L$ score $<5$; Severe deficit: ADL score $<4$

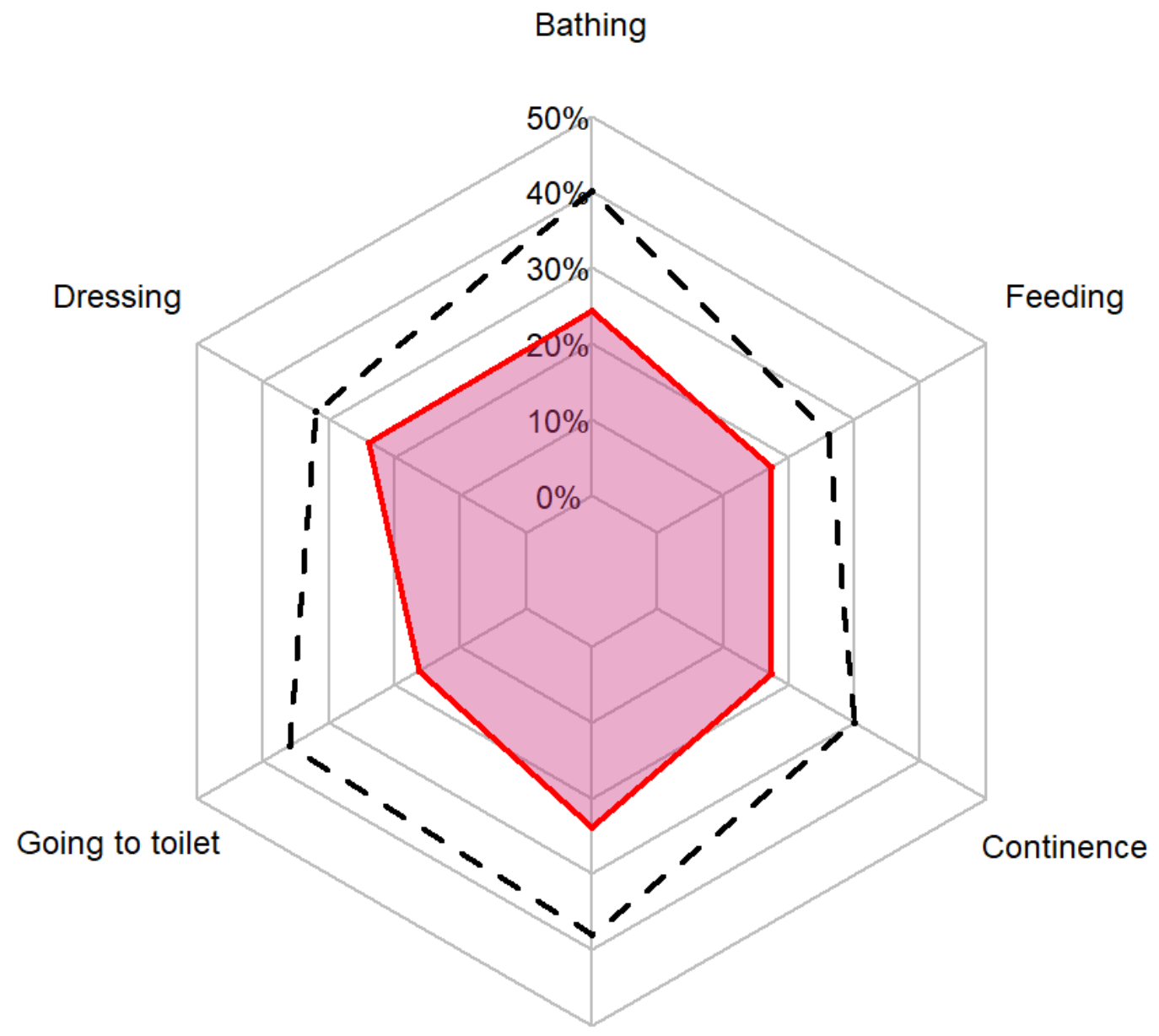

Transfer

\section{Figure 2}

Spider Chart of the decreased autonomy at day 180 Proportion of patients suffering from a loss of autonomy on the different dimension of the ADL (activities of daily living) score. Red line: Rehabilitated patients; Black dotted line: Not Rehabilitated patients.

\section{Supplementary Files}

This is a list of supplementary files associated with this preprint. Click to download.

- GraphicalAbstractFRAGIREHAB.pptx 
- SupplementaryFigure1.tif

- SupplementaryTable1.docx 